\title{
OBSERVATÓRIO SOCIAL DO BRASIL E OS DESAFIOS ORGANIZACIONAIS DO CONTROLE SOCIAL
}

\section{THE SOCIAL OBSERVATORY OF BRAZIL AND THE ORGANIZATIONAL CHALLENGES OF SOCIAL ACCOUNTABILITY EL OBSERVATORIO SOCIAL DEL BRASIL Y LOS DESAFÍOS ORGANIZACIONALES DEL ACCOUNTABILITY SOCIAL}

\section{RESUMO}

Este estudo de caso visa a interpretar as representações sociais que caracterizam o Observatório Social do Brasil, sua identidade, seus desafios e perspectivas organizacionais, na coordenação da Rede OSB de controle social. Para legitimar sua atuação, a organização viabiliza parcerias e adota uma postura de isenção partidária, preservação da imagem do agente público, profissionalização e padronização de procedimentos. Seus principais desafios e/ou perspectivas podem ser mais bem compreendidos considerando suas ambiguidades e complementariedades, ou seja, à luz do pensamento complexo, na abordagem aqui adotada. Para a análise realizada, as representações sociais foram agrupadas conforme três aspectos que tipificam o engajamento em accountability social: estratégia, organização e contexto. A representação social (RS) de negação da política partidária torna complexa a construção, a longo prazo, de pontes duradouras entre sociedade e Estado para a coprodução do bem público controle e evidencia a dificuldade de a própria sociedade organizada construir pontes entre si.

PALAVRAS-CHAVE: Accountability, identidade organizacional, representações sociais, complexidade, coprodução do bem público.

Rodrigo da Silva de Bona ${ }^{1}$

debona.floripa@gmail.com

ORCID: 0000-0002-3576-6626

Sérgio Luís Boeira²

sbsergi0267@hotmail.com

ORCID: 0000-0002-1999-5373

${ }^{1}$ Ministério da Transparência e Controladoria-Geral da União, Florianópolis, SC, Brasil

${ }^{2}$ Universidade Federal de Santa Catarina, Departamento de Ciências da Administração, Florianópolis, SC, Brasil

Submetido 24.02.2018. Aprovado 08.08.2018

Avaliado pelo processo de double blind review

DOI: http://dx.doi.org/10.12660/cgpc.v23n75.73946 


\section{ABSTRACT}

This case study aims at interpreting the social representations that characterize the Social Observatory of Brazil, its identity, organizational challenges and perspectives, under the coordination of Rede OSB of social accountability. To legitimize its performance, the organization enables partnerships and adopts a stance of political-party exemption, preservation of the public agent's image, professionalization and standardization of procedures. Its main challenges and / or perspectives can be better understood considering its ambiguities and complementarities, that is, in the light of complex thinking, in the approach adopted here. For this analysis, the social representations were grouped according to three aspects that typify the engagement in social accountability: strategy, organization and context. The social representation of denial of political parties makes complex the long-term construction of lasting bridges between Society and State for the co-production of the public good, and shows the difficulty of the organized Society itself to build bridges.

KEYWORDS: Accountability, organizational identity, social representations, complexity, co-production of public good.

\section{RESUMEN}

Este estudio de caso pretende interpretar las representaciones sociales que caracterizan al Observatorio Social de Brasil, su identidad, desafíos y perspectivas organizacionales, en la coordinación de la Red OSB de accountability social. Para legitimar su actuación, la organización viabiliza alianzas y adopta una postura de exención partidaria, preservación de la imagen del agente público, profesionalización y estandarización de procedimientos. Sus principales desafíos y/o perspectivas pueden ser mejor comprendidos considerando sus ambigüedades y complementariedades, es decir, a la luz del pensamiento complejo, en el abordaje aquí adoptado. Para el análisis realizado, las representaciones sociales fueron agrupadas según tres aspectos que tipifican el compromiso en accountability social: estrategia, organización y contexto. La representación social de negación de la política partidaria hace compleja la construcción a largo plazo de puentes duraderos entre Sociedad y Estado para la coproducción del bien público control y evidencia la dificultad de la propia Sociedad organizada de construir puentes entre sí.

PALABRAS CLAVE: Rendición de cuentas, identidad organizacional, representaciones sociales, complejidad, coproducción del bien público.

\section{INTRODUÇÃO}

Desde o século XIX, o conceito de controle social (CS) era utilizado principalmente na sociologia como um controle do Estado necessário para garantir coesão, integração e ordem social (Crubelatte, 2004). A partir da década de 1980, o termo passou a ser adotado no Brasil como o controle da sociedade sobre as ações do Estado (Schommer, 2014).

Com o desvelamento de casos de corrupção que causaram indignação popular em cidades do interior do Paraná, em 2006 começaram a ser criadas organizações sociais com função exclusiva de exercer o controle social sobre a administração municipal. Em 2010, cinco delas perceberam a necessida- de de atuar em conjunto e criaram a Rede OSB, coordenada pelo Observatório Social do Brasil (OSB). Os denominados Observatórios Sociais (OS) utilizam uma "metodologia de monitoramento das compras públicas" municipais, "desde a publicação do edital de licitação até o acompanhamento da entrega do produto ou serviço" (OSB, 2017a).

Com uma sistemática manualizada pela consultoria da PriceWaterHouseCoopers, em pouco mais de uma década a rede alcançou 134 OS em 16 Estados (até junho/2018), monitorando os poderes Executivo e Legislativo municipal. Diferentemente dos OS, a organização OSB não acompanha a gestão de uma cidade, mas atua na sua coordenação, articulação e expansão da rede nacional, firmando parcerias estratégicas e oferecendo 
um modelo padronizado de trabalho aos observatórios filiados. Estatutariamente, a diretoria e os conselhos do OSB são compostos por representantes de OS, ou seja, o OSB representa a Rede OSB em termos institucionais.

O OSB estima que em quatro anos (20132016) tenha havido "uma economia de mais de $R \$ 1,5$ bilhão para os cofres municipais" (OSB, 2017a). A metodologia de cálculo desse valor, porém, é controversa entre os próprios voluntários. Existem economias quantificáveis, mas há aquelas cujos resultados estendem-se para além da ação do observatório, como ganhos decorrentes do aumento de participantes em licitações, melhorias em procedimentos gerenciais, avanços políticos junto ao Legislativo e ações de educação para a cidadania.

Na prática, cada OS tem suas peculiaridades e desafios, o que faz variarem sobremaneira suas linhas de atuação: alguns fiscalizam somente a prefeitura, outros priorizam - Legislativo e só parte deles consegue fazer as duas coisas. Enquanto a maioria monitora somente os editais de compras e contratações, poucos conseguem acompanhar a folha de pagamento, que geralmente ultrapassa $50 \%$ do orçamento municipal. E mesmo com o crescimento da rede, emergem conflitos pessoais e divergências organizacionais não identificadas por grande parte dos observatórios, nem pela mídia, a sociedade em geral ou os agentes públicos que interagem com a rede.

O fenômeno dos OS transforma a postura da sociedade frente à realidade: da inação e passividade à ação concreta, que traz resultados consistentes. Isso porque é ao mesmo tempo causa e efeito, expressa uma mudança de postura e também contribui para gerar mais mudanças. O Observatório Social é expressão e, ao mesmo tempo, parte do fenômeno do controle estatal realizado por meio de organizações sociais.

O próprio slogan da rede indica essa mudança: "Indignar-se é importante. Mas atitude é fundamental" (2017b). O voluntário admite que apenas o discurso não é suficiente para mudar a realidade; é preciso agir efetivamente. Mas quais as características desse fenômeno social organizado? Como a rede constrói sua credibilidade? Que valores e sentimentos os voluntários compartiIham ao construir sua realidade social e sua identidade organizacional? Que desafios e perspectivas emergem no OSB, como coordenador da rede?

Este trabalho aborda o controle social sob uma perspectiva organizacional, tendo como objeto a entidade OSB. Além de análise documental, para aprofundar a investigação sobre uma organização que, por sua natureza, é composta por outras, optou-se por realizar entrevistas levando em conta perspectivas externas, divergentes e/ou complementares sobre o OSB, coerente com a abordagem do pensamento complexo aqui adotada (Morin, 1991; 1998; 2015).

Essa contextualização permite elaborar a questão de pesquisa: Quais representações sociais caracterizam o Observatório Social do Brasil, sua identidade, seus desafios e perspectivas organizacionais, na coordenação da Rede de Observatórios municipais de controle social? Para responder a esta pergunta, o trabalho tem como objetivo identificar e interpretar as representações 
sociais que caracterizam o OSB, sua identidade, seus desafios e perspectivas organizacionais, na coordenação da Rede OSB.

A compreensão do fenômeno do controle social realizado por organizações constituídas especificamente para esta finalidade pode contribuir com os estudos sobre o tema, com o aperfeiçoamento de iniciativas similares da sociedade civil e de políticas públicas de fomento à participação e accountability. O portal da rede contém a "Carta de Identidade dos OS" (OSB, 2017a), elaborada no 10. Encontro Nacional por 49 Observatórios (10. ENOS, 2012), que definiu princípios e objetivos, como o apartidarismo e a vedação ao recebimento de recursos de órgãos públicos fiscalizados. Contudo, sua identidade organizacional (Etkin \& Schvarstein, 2005) não tem sido investigada, no "melhor entendimento de sua complexidade e sua utilização mais abrangente na análise organizacional" (Wood \& Caldas, 1997).

As pesquisas sobre a rede não abordam as representações sociais (RS) dos voluntários, as quais contribuem na forma como o conhecimento coletivo é construído e disseminado nessas organizações. Caracterizadas pelas interações humanas entre indivíduos e grupos (Moscovici, 2015), as RS "são sistemas de ideias, valores e práticas construídos por grupos sociais, com a dupla função de orientação e de comunicação" (Jovchelovitch \& Priego-Hernandez, 2013, p. 31). A questão da legitimidade é central para o OSB. Segundo Nogueira e Alves (2014, p. 5), "a ação conjunta organizada" entre entidades associativas e/ou cooperativas não só dá "mais poder, mas muitas vezes mais legitimidade para conseguir uma influência externa". No caso dos OS, essa influência e credibilidade visam a garantir mantenedores, facilitar o acesso a informações públicas e aumentar a respeitabilidade que viabiliza parcerias em diversas instâncias.

Os observatórios buscam ser representantes legítimos da sociedade local, ainda que não se articulem com segmentos sociais muito variados. Todas essas questões afetam a identidade dessa rede em expansão, e a compreensão das RS permite ir além dos registros formais e documentos oficiais, que não traduzem a realidade empírica das organizações.

\section{REFERENCIAL TEÓRICO}

A fundamentação deste trabalho parte do paradigma da complexidade, ou pensamento complexo, proposto por Edgar Morin, seguida de uma breve revisão sobre representações sociais. Em seguida, são delimitados os conceitos de controle social, accountability e coprodução do bem público, no contexto dos estudos sobre a Rede OSB.

\section{Paradigma da complexidade}

O pensamento aberto para a complexidade (Morin \& Kern, 1995) facilita a compreensão da interdependência entre atores, processos, sociedade, Estado e organizações, alertando para a necessidade de uma análise permanentemente crítica, visando a evitar o reducionismo, o determinismo, a disjunção e a unilateralidade entre os níveis ou dimensões dos fenômenos individuais, coletivos e organizacionais que se investigam. Para Morin (1998, p. 192):

O imperativo da complexidade é, também, o de pensar de forma organizacional; é o 
de compreender que a organização não se resume a alguns princípios de ordem, a algumas leis; a organização precisa de um pensamento complexo extremamente elaborado.

Segundo Morin, as relações no interior de uma sociedade, em geral, assim como nas organizações, em particular, são ao mesmo tempo antagônicas e complementares. Essa "complementaridade antagônica" está "baseada numa ambiguidade extraordinária" (Morin, 2015, p. 91). Para o autor (p. 87):

Não temos de um lado o indivíduo, de outro a sociedade, de um lado a espécie, do outro os indivíduos, de um lado a empresa com seu diagrama, seu programa de produção, seus estudos de mercado, de outro seus problemas de relações humanas, de pessoal, de relações públicas. Os dois processos são inseparáveis e interdependentes.

O pensamento complexo não é paradoxal. $O$ que Morin defende é uma abordagem racional que não expulse as contradições, os paradoxos, mas seja acolhedora destes, para compreendê-los. Para ele (Morin, 1991, p. 160), "a contradição que nos interessa não é, evidentemente, a que aparece num raciocínio incoerente, ou que provém de uma falta de racionalidade. É aquela que faz com que surja o raciocínio racional."

Assim, tendo como lente teórica a abordagem complexa aqui adotada, pretende-se investigar, por meio das representações sociais, nuances variadas e diversas sobre a identidade organizacional, os desafios e as perspectivas do OSB.

\section{Representações sociais}

Existem diferentes abordagens teóricas sobre as RS, que também podem ser compreendidas como fenômeno a ser pesquisado ou enquanto recurso metodológico (Jovchelovitch, 2008), sendo esta última a abordagem aqui realizada, pelo que não se pretende abordar a teoria das representações sociais (TRS). Respeitado o limite da generalização e da própria interpretação (Arruda, 2002), as RS são um caminho para tratar de temas socialmente complexos e ambivalentes, como os que envolvem a administração pública.

Para Jodelet (2009; 2011) e Arruda (2005), as RS permitem ao indivíduo compreender e reinterpretar o mundo que o rodeia e, por meio da comunicação dialógica com os demais indivíduos do seu grupo, compartilhar um significado comum com os membros dessa sociedade. Segundo Jodelet (2001), as RS "são fenômenos complexos sempre ativados e em ação na vida social", como uma "forma de conhecimento, socialmente elaborada e partilhada, com um objetivo prático, e que contribui para a construção de uma realidade comum a um conjunto social" (p. 22). Um desses objetivos práticos é permitir aos indivíduos posicionarem-se sobre a realidade, decidirem sobre como devem se comportar na sua relação com o mundo cotidiano.

Considerando o indivíduo como ator social responsável pela criação e compreensão da realidade, para Moscovici (2015), o sujeito precisa ser interpretado enquanto ser social que age, pensa e sofre influências do grupo e da realidade social em que está inserido, mas cuja ação e pensamento ao mes- 
mo tempo influenciam o grupo e ajudam a construir essa mesma realidade social. "Isso significa que representações compartilhadas, sua linguagem, penetram tão profundamente em todos os interstícios do que nós chamamos de realidade" que podemos dizer que elas "constituem" essa realidade (p. 212).

Essas definições partilhadas da realidade entre indivíduos de um determinado grupo contribuem para a construção da visão que esse grupo tem do real. As RS são representações da realidade e são, ao mesmo tempo, a própria realidade social construída em um determinado grupo, já que "toda a realidade é representada e apropriada por indivíduos ou grupos", e, assim, "reconstruída no seu sistema cognitivo, integrada no seu sistema de valores, dependente da sua história e do contexto social e ideológico que os envolve" (Lopes \& Bueno, 2007, p. 94).

As RS da realidade tornam-se guias para a ação, como "processos sociocognitivos, dependentes do sujeito, mas influenciados pelas condições sociais" nas quais são elaborados e transmitidos (p. 92). Há uma compreensão da complexidade e ambivalência existentes na relação entre indivíduo e sociedade, que são articulados mas não se confundem, assim como entre a dimensão particular e pública.

\section{Controle social e accountability}

Desde o século XIX, o conceito de controle social (CS) era utilizado principalmente na sociologia como um controle do Estado necessário para garantir coesão, integração e ordem social (Crubelatte, 2004). A partir da década de 1980, o termo passou a ser adotado no Brasil como controle político-administrativo da sociedade civil sobre as atividades do Estado (Schommer, 2014).

A Constituição de 1988 incluiu diversos instrumentos participativos no Brasil, como a ação civil pública, as audiências públicas e os conselhos gestores e fiscalizadores (Enap, 2015). Mais recentemente, a aproximação entre o Estado e a sociedade tem evoluído, com a vigência da Lei de Acesso à Informação em 2012 e o advento do Código de Defesa do Usuário de Serviços Públicos em 2017 (Lei no. 13.460), que abrem novos canais e definem prazos de comunicação entre o cidadão e poder público, com os serviços de informação ao cidadão e as ouvidorias governamentais.

Esta pesquisa investiga o controle social como expressão da capacidade de exercício da cidadania, partindo da concepção dessa como processo de conquista popular, em que a sociedade adquire consciência e organização para realizar seus próprios projetos (Demo, 1992). Nessa abordagem, mais do que contribuir esporadicamente com seu voto nas eleições, o cidadão tem o dever-direito de atuar enquanto instância máxima e legítima no acompanhamento das ações do Estado, em âmbito administrativo, político, econômico e social.

Rocha et al. (2012) e Schommer (2014) estudaram o controle social realizado pelos OS enquanto coprodução (Ostrom, 1996) do controle, este como "bem público essencial à accountability em uma nova relação Sociedade-Estado." Para Rocha et al. (2012, p. 2) accountability pode ser compreendida "como obrigação de uma pessoa ou grupo 
de prestar contas por sua conduta diante de uma responsabilidade assumida perante outrem." Rocha (2011) aponta diferentes entendimentos de accountability institucional e social, conforme os modelos de Administração Pública: Administração Burocrática, Nova Gestão Pública e Novo Serviço Público (Denhardt \& Denhardt, 2003; Denhardt, 2012).

O Novo Serviço Público (NSP) pressupõe uma relação cooperativa entre Estado, sociedade, mercado e demais partes interessadas (stakeholders), baseada no apoio mútuo, no compartilhamento decisório e no alargamento da compreensão de accountability. Por ser "complexa, multifacetada e processual", a accountability inclui "dimensões substantivas e instrumentais, técnicas e políticas, e depende de diversidade de sujeitos e mecanismos para ser produzida" (Heidemann, 2009, p. 2).

Doin et al. (2012) evidenciaram a coprodução da informação e do controle pelos OS, ocasionando a interação entre os mecanismos de accountability para além da metáfora geométrica horizontal-vertical, em uma perspectiva sistêmica, com "múltiplas interações dos mecanismos de controle institucional e de controle social e seus agentes, influenciando-se mutuamente, demandando e produzindo informações e estabelecendo a coprodução do bem público controle" ( $p$. 8).

Schommer et al. (2015) pesquisaram "características da coprodução da informação e do controle sociopolítico sobre a administração pública nas relações entre OS brasileiros $\mathrm{e}$ órgãos estatais de controle", analisando 20 OS e três em particular (Maringá, Itajaí e
São José). Para além da compreensão vertical e horizontal (O'Donnell, 1998), os autores propuseram "uma perspectiva sistêmica da accountability", em "quatro categorias: política-cultural; valorativa; organização sistêmica e produção" (Schommer et al., 2015, p. 1376). Assim, fundamentado no pensamento complexo de Morin e a partir da identificação e interpretação das RS, busca-se abordar o controle social enquanto fenômeno socio-organizacional complexo, visando a conhecer a identidade no OSB, seus principais desafios e suas perspectivas.

\section{METODOLOGIA}

Este estudo de caso qualitativo exploratório, descritivo e interpretativo, enquanto "possibilidade de investigação dos fenômenos humanos e sociais" (Godoy, 2006, p. 116), viabiliza "explorar e entender o significado que os indivíduos ou os grupos atribuem a um problema social ou humano" (Creswell, 2010, p. 26).

A escolha do OSB como caso para estudo levou em conta que essa organização representa a Rede de Observatórios Sociais, portanto investigar a identidade, os desafios e as perspectivas do OSB significa, em certa medida, investigar esses aspectos da Rede OSB em geral, e de cada OS em particular. Além disso, embora a rede esteja em franca expansão, emergem conflitos pessoais e divergências organizacionais. A maioria dos OS catarinenses, por exemplo, tinha o Observatório Social de São José (OSSJ) como referência; seu vice-presidente atual era membro do Conselho Fiscal do OSB até 2016. Mas houve um rompimento entre $O$ OSB e o OSSJ, que não está mais na rede desde janeiro de 2017 (OSB, 2017b). Esses 
conflitos, porém, não são claros para grande parte dos observatórios, nem para a mídia, a sociedade em geral e os agentes públicos que interagem com a rede. Alguns voluntários e autoridades de órgãos parceiros não sabem que o OSSJ não é da rede, já que, além do mesmo nome, utiliza a mesma logomarca, apesar de não constar na lista publicada pelo OSB em seu website.

\section{Entrevistas}

A alternativa metodológica adotada para a investigação proposta foi a identificação e interpretação das representações sociais (Jodelet, 2009; 2011; Arruda, 2005), a partir dos dados coletados em nove entrevistas focalizadas e semiestruturadas (Sierra, 1998), de modalidade mista, incluindo perguntas padronizadas de resposta aberta (Godoi \& Mattos, 2006). Os entrevistados são voluntários em OS - exceto um, contratado em cargo diretivo no OSB - e a maneira como esses diferentes sujeitos veem e constroem a realidade social é atrelada às $\mathrm{RS}$ que cada um possui, como ator social de um grupo.

Este artigo aborda uma rede de organizações sociais em expansão e sua identidade em construção. São entidades autônomas espalhadas por diversos Estados e que tentam seguir uma metodologia padronizada. Mas cada OS é único, com peculiaridades derivadas de suas diferentes linhas de atuação e da personalidade da liderança do respectivo OS. Esta investigação sobre as RS características de organizações de controle social tem a entidade OSB como objeto principal, mas leva em conta as percepções de voluntários de um OS que não faz mais parte da rede, visando a abordar a temática numa ótica organizacional complexa e mul- tifacetada.

Com base em observação direta (Vergara, 2010) realizada durante o Encontro Estadual de OS Catarinenses de 2017, priorizou-se entrevistar lideranças do OSB que fossem membros de conselhos ou vice-presidentes de OS de Santa Catarina. Para elaboração das questões, foi realizada análise documental (Cellard, 2008), considerando-se ainda:

- os principais conceitos identificados nos

artigos sobre o tema;

- as diferentes linhas de atuação dos OS;

- as divergências ocorridas entre OSB e OSSJ entre 2016 e 2017;

Os entrevistados foram selecionados em uma amostra teórica ou discursiva (Sierra, 1998): partindo da proposta de dialogar com as principais lideranças do OSB e do OSSJ, variando o perfil dos escolhidos conforme seu segmento de origem - servidores públicos, aposentados, empresários e um funcionário contratado -, a seleção dos entrevistados e a profundidade das conversas evoluíram ao longo da sua execução.

Buscou-se uma diversidade de perfis, visando a abordar controvérsias, captar diferentes percepções e pontos de vista, coerentemente com a fundamentação teórico-epistemológica desta pesquisa. Assim, no período de 01/08/2017 a 03/10/3017, foram entrevistados quatro voluntários do OSSJ, quatro do OSB (três presidentes de OS de SC e um do Paraná) e um contratado do OSB, conforme resumido no Quadro 1 e como segue:

- 1 contratado do OSB, experiente em entidades empresariais e voluntariado;

- 2 empresários das áreas de indústria e comércio;

- 1 empresário e profissional liberal de 
serviços contábeis;

- 1 estudante, profissional liberal do direi-

to e ex-servidor comissionado;

- 2 servidores públicos militares aposentados;
- 2 servidores públicos ativos, concursados em órgãos de controle estatal;

- Idade média dos entrevistados: 54 anos.

Quadro 1. Resumo das características dos entrevistados

\begin{tabular}{|c|c|c|c|c|c|c|c|c|c|}
\hline & (E1) & (E2) & (E3) & (E4) & (E5) & (E6) & (E7) & (E8) & (E9) \\
\hline Ambiente & $\begin{array}{l}\text { Pessoal } \\
\text { In Loco }\end{array}$ & $\begin{array}{l}\text { Pessoal } \\
\text { In Loco }\end{array}$ & $\begin{array}{l}\text { Pessoal } \\
\text { In Loco }\end{array}$ & Skype & Skype & Skype & Skype & Skype & Skype \\
\hline $\begin{array}{l}\text { Duração } \\
\text { (min) }\end{array}$ & 146 & 62 & 90 & 48 & 87 & 126 & 123 & 78 & 85 \\
\hline $\begin{array}{l}\text { OS onde } \\
\text { atua }\end{array}$ & $\begin{array}{c}\text { OS } \\
\text { São José }\end{array}$ & $\begin{array}{c}\text { OS } \\
\text { São José }\end{array}$ & $\begin{array}{c}\text { OS } \\
\text { São José }\end{array}$ & $\begin{array}{l}\text { OS } \\
\text { São } \\
\text { José }\end{array}$ & OSB & OSB & $\begin{array}{l}\text { OS } \\
\text { Brus- } \\
\text { que }\end{array}$ & $\begin{array}{c}\text { OS } \\
\text { Imbitu- } \\
\text { ba }\end{array}$ & $\begin{array}{l}\text { OS } \\
\text { Itajaí }\end{array}$ \\
\hline $\begin{array}{l}\text { Tempo no } \\
\text { OS/OSB }\end{array}$ & 2009 & 2016 & 2012 & 2011 & 2010 & 2008 & 2009 & 2013 & 2012 \\
\hline
\end{tabular}

A interpretação é o principal recurso heurístico para estudo das RS, pois identificar e compreender a RS é, em si, um exercício de interpretação, uma costura intangível e integradora do olhar do pesquisador sobre o universo de informações processadas (Arruda, 2005). Buscando consistência, a pesquisa preocupou-se em coletar e sistematizar indícios que conduzissem a cada interpretação, permitindo, de modo transparente, o acesso aos caminhos utilizados no processo interpretativo. Segundo Arruda, "além do rigor, a experiência aliada à sensibilidade parecem ser duas das mestras" do ofício de interpretar (2005, p. 229).

No estudo de caso qualitativo, o pesquisador define quando ocorre a saturação de dados (Godoy, 2006), e a análise ainda em campo facilitou essa tarefa. Adotou-se o "percurso da interpretação" sistematizado por Arruda
(2005, p. 249), visando a identificar as RS emergentes e compreender qual o seu significado, a "lógica informal da vida cotidiana" (p. 252). Como reforço, a triangulação (Vergara, 2010) representou um esforço de, por meios distintos, evidenciar o que se afirma sobre um fenômeno, sem pretender uma conclusão definitiva.

\section{INTERPRETAÇÃO DOS DADOS}

O primeiro OS foi criado em Maringá/PR no ano de 2006 e o OSB foi fundado em 2008 na mesma cidade, mas desde 2012 tem sede em Curitiba, no Paraná. Em 2016, a atual gestão iniciou um planejamento para delinear as estratégias da Rede OSB para os próximos dez anos, incluindo o objetivo de estar presente nas 309 cidades brasileiras com mais de 100 mil habitantes. Em junho/2018, dos 134 OS existentes, quase me- 
tade estava em cidades desse porte, sendo que mais de $70 \%$ deles estão em cidades entre 50 mil e 500 mil habitantes.

À luz dos pressupostos adotados, a interpretação realizada permitiu classificar as RS identificadas em 16 grupos, somando 448 registros brutos que indicam padrões de conceitos e expressões, conforme resumido na Tabela 1. Essas RS identificam a organização OSB, em específico, os Observatórios Sociais e a Rede OSB, hipótese de generalização limitada, visto que se priorizou a profundidade da pesquisa e o peso dos cargos ocupados pelos pesquisados, em vez de um número representativo de entrevistas.

Tabela 1. Grupos de representações sociais identificados

\begin{tabular}{|c|c|c|}
\hline Prisma & Grupos de Repres. Sociais & $\begin{array}{l}\text { Qt. Regis- } \\
\text { tros }\end{array}$ \\
\hline \multirow{8}{*}{$\begin{array}{l}\text { RS Sobre } \\
\text { Identidade e Estratégia Organizacional (*) }\end{array}$} & Observatório Social do Brasil & 19 \\
\hline & Rede OSB & 11 \\
\hline & Observatório Social & 27 \\
\hline & Estratégia $\left(^{*}\right)$ & 20 \\
\hline & Resultados do OS & 32 \\
\hline & Identidade $\left(^{*}\right)$ & 50 \\
\hline & Representatividade & 8 \\
\hline & Responsabilidade Social & 14 \\
\hline \multirow{4}{*}{$\begin{array}{l}\text { RS Sobre as } \\
\text { Relações de Coprodução } \\
\text { Sociedade-Estado }\end{array}$} & Controle Social & 23 \\
\hline & Voluntariado & 38 \\
\hline & Corrupção e Ineficiência Pública & 50 \\
\hline & Política e Apartidarismo & 39 \\
\hline \multirow{4}{*}{$\begin{array}{l}\text { RS Sobre as } \\
\text { Interações Sociais (Indivíduos e Grupos) }\end{array}$} & Receptividade ao OS & 21 \\
\hline & Conflitos & 26 \\
\hline & Desafios/Riscos/Ameaças & 30 \\
\hline & Críticas e controvérsias & 40 \\
\hline \multicolumn{2}{|c|}{ Total de registros - conceitos e expressões } & 448 \\
\hline
\end{tabular}

(*) Os termos Estratégia e Identidade foram utilizados para nominar grupos específicos de RS identificados. Porém, outros grupos também representam aspectos de Identidade e Estratégia organizacional. Dessa forma, os termos foram adotados também para definição de um dos prismas, em sentido amplo, englobando oito grupos.

\section{Características do OSB}

A interpretação dos dados obtidos permitiu caracterizar 12 aspectos que compõem a identidade da organização OSB, relatados com termos e analogias utilizadas pelos próprios entrevistados:

a)Articulação: o OSB "surgiu como um guar- da-chuva, tentando organizar uma rede" (E2) que pudesse auxiliar entidades locais a fundar OS, principalmente associações empresariais. É um "aliado dos OS" (E6), assessora, dá "prestígio", "força" e "segurança" (E7), busca "dar maior estrutura para os observatórios" e tem função de "estabelecer metas e parâmetros para a rede" (E9); 
b) Guardião dos princípios: destaca-se a importância da "unicidade, da uniformidade de atuação, de identidade, de princípios" (E8). "O OSB tem princípios", e seus conseIhos são "só de pessoas dos OS" (E5). "O OSB tem o papel de ser articulador e guardião dos princípios da rede" (E5). "O OSB é a rede", "só existe porque tem a rede" (E6), para atender à rede;

c) Alinhamento: "é como uma federação" de OS (E6): "se algum OS não comunga" dos princípios, "ele não deve fazer parte da rede" (E9). A identidade organizacional vem sendo construída com uma estratégia de abordagem positiva, propositiva, colaborativa, centrada em evitar o conflito, "não expor a figura do administrador público" (E9), a bem da "credibilidade" (E6, E7, E8, E9) necessária junto aos gestores públicos;

d) Legitimidade (do OSB perante a rede): nos Conselhos de Administração, Superior e na Presidência "do OSB só tem OS", por isso essa "federação" - o OSB - é legitimada pela base de OS (E6). É uma "proposta parecida com Lions, Rotary, Maçonaria," organizações que "têm coordenações centrais", mas têm capilaridade e "autonomia local" (E7);

e) Representatividade (ou legitimidade dos OS): um dos princípios fundamentais do OSB e da rede (E2, E5, E6, E7, E8): "os mais bem-sucedidos são os que têm mais representatividade" de entidades locais, e cabe ao OSB a articulação de parcerias nacionais que possam ser ampliadas em nível local, a exemplo da OAB, CRC etc. (E6). É a principal estratégia de legitimação do controle social. Por isso buscam "congregar outras entidades, (...) para ter legitimidade de representar" (E7);

f) Neutralidade: outra estratégia para legitimar o controle social é a autoafirmação de "neutralidade", "equilíbrio", "imparcialidade", "isenção" (E2, E6, E7, E8, E9), decorrentes de um distanciamento entre política e técnica: "a gente faz uma análise técnica" (E7). "A vedação de aceitar pessoas filiadas a partidos políticos, como associado e como membros da diretoria, foi uma regra importantíssima para o sucesso dos observatórios" (E1);

g) Credibilidade: "é muito mais adequado para a rede sermos vistos como uma entidade que tem esses padrões, do que uma entidade que não tem, onde (...) pode fazer tudo" (E8). "Essa seriedade, essa estabilidade (...) pode fazer com que as pessoas acreditem que a participação é (...) a única forma de se mudar" (E7);

h) Padronização: o OSB é responsável pela padronização de procedimentos na rede, que "tem de seguir, não por obrigação, mas por achar válido" (E8), porque "não dá para uma organização crescer sem um mínimo de organização" (E8); afinal, se "cada um faz de um jeito", "pode comprometer todo o trabalho" (E8);

i) Profissionalização: é necessário "profissionalizar para ter continuidade", "manter o histórico para as trocas de gestão", dar aos OS "suporte, sistemas, alianças." "Não depender de voluntários", somente como conselheiros, consultores, para "decisões estratégicas" (E6), pois muitos deles são profissionais nas áreas de atuação ou em temas correlatos ao OS; 
j) Consolidação: o OSB está institucionalizando o controle social (E8). Há "52 OS em processo de abertura". "A gente não sai batendo palmas na cidade: 'quem quer abrir?', (...) "só atende demanda que vem, e já é muito grande" (E6). "Nos próximos 5 anos", "vamos alcançar 500 cidades, incluindo todas as capitais e as que têm mais de 100 mil habitantes", com OS regionais, "que também cuidam de cidades vizinhas." Cidades com "menos de 20 ou 30 mil habitantes não têm condições" de manter um OS (E6);

k) Sustentabilidade econômica: para que o OSB não dependa de contribuições dos OS, muitos dos quais mal conseguem arrecadar fundos suficientes para si próprios, pode haver uma tendência de o OSB "ir para São Paulo", para o "centro financeiro" do país (E9), o que poderia facilitar a viabilidade econômica das estratégias traçadas. "Poderia ser Brasília" mas querem "distância da política" (E9);

I) Maçonaria: os principais mantenedores "em muitas cidades" são "maçonaria, entidades empresariais, $O A B$, órgãos públicos, Receita Federal". "Se nasce no meio empresarial é mais forte, dura mais, mais isento. Maçonaria são empresários, né (...) mas também tem servidor público, contadores e advogados na maçonaria" (E7). Muitos voluntários de diversos meios seguem essa tradição, que traz "respeito", "como o OS Chapecó," que está "se fortalecendo, com pessoas importantes, (...) a maçonaria está muito envolvida, entidades empresariais, vai chegar com muita força" (E7). Visando a "propagar a verdade, a razão e a transparência", um entrevistado recebeu a "missão" do seu grão-mestre de disseminar a criação de OS pelas cidades catarinenses (E9).
Desafios e perspectivas organizacionais

Os principais desafios referem-se a questões de governança do OSB e da rede, bem como de cada OS em particular, e estão aqui agrupados didaticamente conforme três aspectos ou variáveis que influenciam nos resultados da accountability social realizada pela Rede OSB: estratégia, organização e contexto. A variável estratégia está associada à capacidade de determinada organização adotar estratégias complexas; a variável organização refere-se à sua adaptabilidade organizacional interna e disposição para o aprendizado, enquanto o contexto inclui a capacidade da entidade de adaptação ao ambiente externo e de estabelecer parcerias com outros atores sociais (Guerzovich \& Schommer, 2016).

Porém, as delimitações entre essas variáveis não são precisas: sua interação "é uma fronteira na literatura sobre a accountability social" (Guerzovich \& Schommer, 2016, tradução livre). Algumas RS incluídas em estratégia poderiam ser classificadas como parte da organização, e vice-versa. Mas esses conjuntos estão intimamente relacionados e o agrupamento didático aqui proposto levou em conta a predominância do impacto da RS neste ou naquele conjunto. Além disso, essas variáveis estão ligadas aos referenciais teóricos de accountability e coprodução do bem público (Guerzovich \& Schommer, 2016), e podem ser mais bem compreendidas considerando suas ambiguidades e complementariedades, ou seja, à luz do pensamento complexo.

\section{Estratégia}

- Representatividade: o OSB "tenta se firmar 
como entidade representativa dos OS", "uma federação", mas precisa que "estejam fortes", "ajudá-los para ser ajudado" (E1);

- Credibilidade: a participação não é isenta de riscos: até onde vai a supremacia do controle social? O cidadão pode tudo em nome de um OS? Pode impor sua posição ao gestor? Limites da liberdade de opinião do cidadão, no espaço público representado pelo OS, em contraposição à presunção de boa-fé e ao direito de defesa do gestor;

- Perfil das lideranças: "o OS é a cara do (...)" (E5, E6, E7, E9), "mas não pode ser", "é um risco que infelizmente em algumas cidades nós temos" (E5). A abordagem mais ou menos colaborativa também "é uma questão (...) do perfil de quem está dirigindo o observatório." Ou seja, "um gestor com um olhar mais contábil, vai migrar para essa linha, então o resultado vai ser positivo nessa linha." (...) "Um gestor que tem uma base e um perfil mais de mobilização comunitária vai atuar mais diretamente no serviço públi$c 0$, que foi a base dele" (E3);

- Mensuração de resultados: é um desafio para o OSB estabelecer indicadores que permitam avaliar suas próprias atividades, tornando-o mais accountable interna e externamente, reforçando sua legitimidade junto aos OS que compõem a rede e consolidando sua credibilidade perante o poder público e a sociedade em geral.

\section{Organização}

- Consolidação: mesmo com as expectativas de crescimento, a consolidação da credibilidade da rede e do OSB como entidade coordenadora passa por "aumentar a atenção aos observatórios que estão com dificuldades" (E1), auxiliar na estabilização dos OS já existentes, sob risco de um OS inativo ser usado como "atestado de honestidade" (E1) pelo gestor local. "Precisa carregar essa cruz, já que se dispõe a isso" (E8). "Tem OS que me parece que é uma ou duas pessoas. Não tem captação de recursos, não tem um escritório" (E8). "Dos 100 ou 120 que nós temos, existe um grande número de observatórios que foram fundados e nunca entraram em operação." Outros "foram criados, chegaram a funcionar, mas morreram depois do primeiro, segundo, terceiro ano" (E1);

- Profissionalização: essencial para legitimação da rede como forma de garantir trabalhos técnicos, imparciais, sua urgência é também uma questão de continuidade. Favretto (2017) identificou que $20 \%$ dos 62 OS pesquisados não têm funcionários, enquanto quase $48 \%$ têm apenas uma pessoa e somente $3 \%$ têm quatro ou mais colaboradores fixos. "Precisa de pessoal técnico somente para atender ao OSB"; "não faz sentido os voluntários atuarem" na "área-meio" (E7). "Precisa profissionalizar porque o voluntário não pode ficar largado. Ele despende algumas horas por semana, precisa de alguém que vá lá na prefeitura (...), precisa desse suporte." (E6). O OS "tem de ter um gestor, tem de captar recursos, tem de ter gestão" (E6);

- Voluntariado: "captação, capacitação e retenção de voluntários" é "uma questão crítica na rede como um todo", o principal "desafio de hoje", porque "muitas pessoas querem contribuir", mas "não desenvolvemos expertise para reter talentos" (E5). "Com estagiários é mais fácil, já é técnico em uma área” (E7). "A realidade do OS é dinâmica, depende das 
lideranças" e "há um desgaste, porque nem sempre conciliam a expertise do voluntário com a necessidade" do OS (E5);

- Sustentabilidade: um OS "precisa apresentar resultados concretos" (E1) para captar recursos e "fidelizar os mantenedores" (E5). Vários OS podem estar "morrendo" por falta de estrutura, decorrente da dificuldade de captação de recursos ou voluntários. O OSB existe "para ajudar os observatórios, ser o representante nacional junto a órgãos públicos, captar recursos internacionais, (...) contratar serviços com ganho de escala" (E1).

\section{Contexto}

- Receptividade: "levamos a proposta do OSB à risca, porque senão lá na frente o observatório acaba se desvirtuando e caminhando para um lado que não é o aconseIhado" (E9). Os entrevistados acreditam que a neutralidade partidária aumenta a receptividade dos gestores ao OS, mas essa receptividade não é uniforme entre as áreas monitoradas nem ao longo do tempo. $\mathrm{O}$ desafio do OSB consiste em auxiliar a rede a melhorar a receptividade e, ao mesmo tempo, manter a neutralidade que dá credibilidade ao OS, sem tornar-se "chapa-branca" (E1) nem convalidar tacitamente atos ilícitos de gestores locais. O dilema está em colaborar, mas criticar e cobrar quando necessário, sem perder sua isenção, para que o gestor mantenha as portas abertas ao OS e respeite suas proposições;

- Parcerias: o OSB tem grande potencial de articulação, comprovado nas parcerias já concretizadas com órgãos nacionais de combate à corrupção. Também tem capa- cidade de articulação local, auxiliando cada OS por meio das entidades representativas mantenedoras, a maioria delas de abrangência nacional e com capilaridade municipal. Mas essas articulações têm sido insuficientes para obtenção de recursos em várias localidades. A consolidação das parcerias pode ser a solução para os desafios de expansão, sustentabilidade financeira e profissionalização da rede;

- Política partidária: predomina a descrença na classe política e um preconceito com a política partidária brasileira. "A gente mesmo fala isso; quando alguém vem aqui já pensamos 'qual será o interesse?' Quer aparecer do lado do observatório" (E2). Os voluntários têm consciência de que "fazer controle social é uma forma de fazer política, só não é política partidária" (E6). Porém, "esse é um campo muito sensível; é pisar em ovos" (E2), pelo "risco de alguém filiado a um partido fazer 'propaganda' de que está no observatório, de que o OS o apoia" (E2). Para a maioria dos entrevistados, "o controle social não deve visar a assumir cargos", ocupar "cadeiras" no Legislativo ou no Executivo, porque "não tem uma bandeira partidária"; "o controle social deve ter a bandeira do cidadão" (E6). A RS predominante é que "nas prefeituras, nos órgãos, nas câmaras, a bandeira é do partido, (...) do interesse pessoal (...) ou do interesse de um grupo, não é o interesse coletivo", enquanto o controle social da rede seria "puro", no sentido de "só ter a bandeira do bem coletivo, do bem comum, e não a bandeira de uma cor partidária" (E6).

\section{CONCLUSÕES}

A interpretação dos grupos de RS sob uma perspectiva complexa resultou na identifica- 
ção de três prismas (Figura 1) por meio dos quais se pode compreender simbolicamente a identidade do OSB, seus desafios e perspectivas organizacionais:

(i) RS sobre identidade e estratégia organizacional;

(ii) RS sobre as relações sociedade-Estado; $\mathrm{e}$

(iii) RS sobre as interações sociais entre indivíduos e grupos na Rede OSB (intra-OS, inter-OS/OSB e extra-rede).

Os três prismas inter-relacionam-se em grupos de RS, ou seja, as relações sociedade-Estado no contexto do controle social municipal exercido na rede coordenada pelo OSB influenciam e são influenciadas pelas RS que constroem a identidade e estratégia dessas organizações, sujeitas, por sua vez, à complexidade das interações sociais entre indivíduos e entre grupos que compõem essas entidades e outras com as quais se relacionam.

Figura 1. Três prismas para compreensão das RS sobre identidade, desafios e perspectivas do OSB

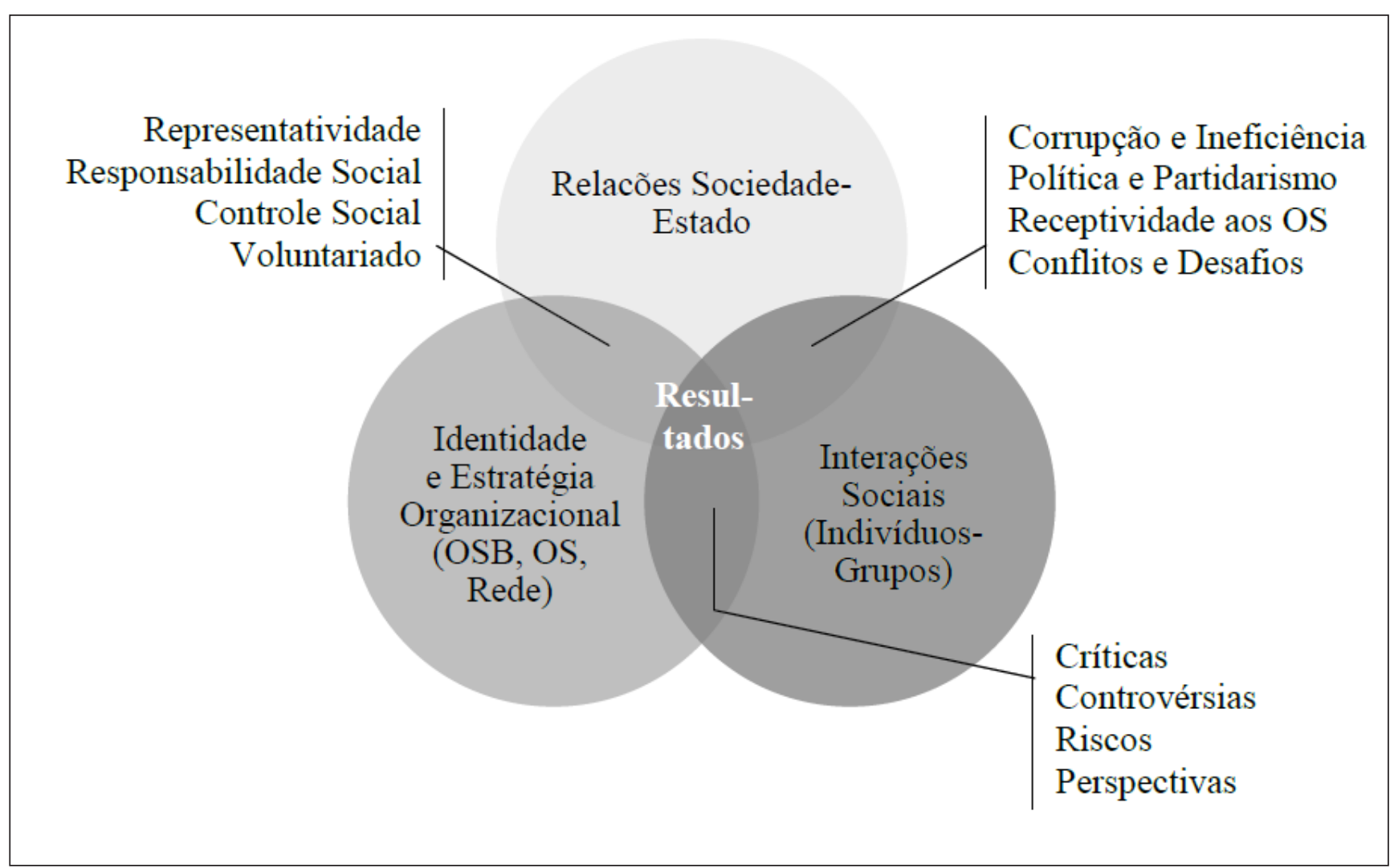

A qualidade dessas interações contribui para o estabelecimento de diferentes tipos de relações entre sociedade e Estado (Guerzovich \& Schommer, 2016). No centro, os resultados potenciais da Rede OSB são fruto da interface desses três prismas, $\mathrm{e}$ podem ser econômico-financeiros, sociais, políticos, éticos e outros, distribuindo-se nas diferentes dimensões sociais em que atua. A complexidade das interações entre os aspectos da identidade organizacional e os desafios e perspectivas do OSB eviden- 
cia as controvérsias dessa organização em construção, pois essa rede de organizações expressa, em maior ou menor medida, os diversos antagonismos e ambiguidades dos contextos nos quais os OS se inserem.

Do total de 16 grupos de RS identificados nos três prismas, merecem destaque, no prisma das Relações sociedade-Estado, os temas Corrupção e Ineficiência Pública, com 50 registros, e Política e Partidarismo, com 39 , que foram assim rotulados e interpretados por dois motivos. Primeiramente, porque a corrupção e a ineficiência são fenômenos que estão na origem da própria razão de ser de um OS e da motivação de seus voluntários. É a indignação com situações comumente encontradas pelos observadores que deu origem à própria Rede OSB. Em segundo lugar, a política e o apartidarismo estão na essência da ação voluntária na rede; a política como ação humana em grupo, compreendida pelos voluntários ouvidos como necessária na busca pela predominância do interesse coletivo.

Somando $20 \%$ do total de 448 registros de RS identificados no contexto do OSB, o destaque dado pelos entrevistados a esses dois grupos pode ser explorado em futuras pesquisas sobre a Rede OSB. A negação e descrença nos partidos são RS unânimes entre os entrevistados, conforme trechos sobre política partidária citados, o que pode indicar que o aparato normativo e o sistema partidário brasileiro talvez não estejam oferecendo espaços confiáveis para o debate de temas relevantes de interesse coletivo local.

\section{CONSIDERAÇÕES FINAIS}

O apartidarismo é visto como princípio fundamental da rede, que deliberadamente busca distanciar-se dos partidos políticos porque não vê na atuação dessas organizações um vislumbre de solução dos problemas sociais locais, tampouco um sincero desejo de defender o interesse público mais amplo. Porém, essa separação entre gestão e política não é coerente com a estratégia de atuação preventiva e colaborativa proposta pela rede. É como se um político que, antes, não merecesse credibilidade por ser filiado a um partido, mas depois de eleito passasse a merecer apoio do OS porque tornou-se gestor.

Ou seja, a negação da política partidária pelos OS não contribui, necessariamente, para a prevenção da corrupção ou a melhoria da eficiência pública que almejam. Afinal é dos partidos que sairão os representantes eleitos que, mais tarde, serão reeducados, orientados, fiscalizados e até mesmo denunciados pelos OS. A aproximação do OSB aos partidos políticos é um "desafio estratégico" (E6) e merece ser objeto de futuros estudos sobre a rede. Há um paradoxo relevante segundo o enfoque do pensamento complexo, entre o princípio apartidário e o princípio da participação social, com ampliação da representatividade como espaço público legítimo. Isso porque, ao excluir do debate determinado segmento (um partido político), o OS já não é mais um espaço tão participativo.

Além disso, negar as organizações partidárias não parece construir, a longo prazo, pontes duradouras entre a sociedade e o Estado, mas apenas demonstrar a dificuldade de a própria sociedade construir pontes para interagir entre ela mesma, a exemplo de organizações como os OS entre si e desses com os partidos políticos. 
Por fim, a interpretação das RS características do OSB, sob uma perspectiva complexa, resultou na sistematização de aspectos de sua identidade, seus principais desafios e suas perspectivas organizacionais na coordenação da Rede OSB. Nesse sentido, esta pesquisa pode contribuir com uma proposta de perfis característicos dos OS, conforme demonstrado no Quadro 2, elaborado a partir das RS sobre o perfil das lideranças e sobre controle social, além de outros aspectos identificados.

Quadro 2. Possíveis perfis de OS conforme perfis das lideranças locais

\begin{tabular}{|c|c|c|c|c|}
\hline $\begin{array}{l}\text { Perfil da } \\
\text { liderança local }\end{array}$ & $\begin{array}{l}\text { Principal linha } \\
\text { de ação }\end{array}$ & $\begin{array}{l}\text { Resultados princi- } \\
\text { pais }\end{array}$ & $\begin{array}{l}\text { Bens públicos } \\
\text { coproduzidos }\end{array}$ & Visão organizacional \\
\hline $\begin{array}{l}\text { Empresarial (habilidades } \\
\text { empresariais) }\end{array}$ & $\begin{array}{l}\text { Busca do aumento } \\
\text { da competitividade, } \\
\text { crescimento econômi- } \\
\text { co local }\end{array}$ & $\begin{array}{l}\text { Aumento do número } \\
\text { de participantes em } \\
\text { licitações }\end{array}$ & $\begin{array}{l}\text { Eficiência, desen- } \\
\text { volvimento econô- } \\
\text { mico local }\end{array}$ & Estratégica-Gerencial \\
\hline $\begin{array}{l}\text { Técnico } \\
\text { (habilidades } \\
\text { técnicas: servidor público, } \\
\text { aposentado, advogado, } \\
\text { contador, engenheiro) }\end{array}$ & $\begin{array}{l}\text { Fiscalização do Exe- } \\
\text { cutivo e do Legisla- } \\
\text { tivo, com ênfase em } \\
\text { compras e gastos }\end{array}$ & $\begin{array}{l}\text { Economias em licita- } \\
\text { ções e contratos sus- } \\
\text { pensos, devoluções } \\
\text { anuais do Legislativo } \\
\text { etc. }\end{array}$ & $\begin{array}{l}\text { Controle, transpa- } \\
\text { rência, economici- } \\
\text { dade, } \\
\text { qualidade do servi- } \\
\text { ço público }\end{array}$ & $\begin{array}{l}\text { Tática- } \\
\text { Operacional }\end{array}$ \\
\hline $\begin{array}{l}\text { Educador visionário (habili- } \\
\text { dades educacionais) }\end{array}$ & $\begin{array}{l}\text { Mobilização social, } \\
\text { educação para a } \\
\text { cidadania, crianças e } \\
\text { adultos }\end{array}$ & $\begin{array}{l}\text { Escolas, alunos al- } \\
\text { cançados, cidadãos } \\
\text { mobilizados, mais } \\
\text { voluntários }\end{array}$ & $\begin{array}{l}\text { Transparência, } \\
\text { cidadania e partici- } \\
\text { pação }\end{array}$ & Estratégica \\
\hline $\begin{array}{l}\text { Político [não partidário] } \\
\text { (habilidades inter-relacio- } \\
\text { nais) }\end{array}$ & $\begin{array}{l}\text { Acompanhamento } \\
\text { das atividades polí- } \\
\text { ticas, principalmente } \\
\text { legislativas, não in- } \\
\text { cluindo gastos }\end{array}$ & $\begin{array}{l}\text { Transparência do } \\
\text { vereador, produção } \\
\text { legislativa, presença } \\
\text { em plenário }\end{array}$ & $\begin{array}{l}\text { Cidadania, repre- } \\
\text { sentativida } \\
\text { de, legitimidade e } \\
\text { transparência }\end{array}$ & Estratégica \\
\hline
\end{tabular}

Esses tipos de perfis identificados (OS empresarial, técnico, educador e/ou político) não são estanques, não ocorrem de forma isolada num mesmo OS, pois uma diretoria com quatro lideranças já pode ter um perfil misto, com todos esses aspectos bem distribuídos, permitindo ao OS atuar com mais abrangência. Ou podem haver, por exemplo, duas lideranças proeminentes em um mesmo OS, que, possivelmente, terá nessas duas linhas o seu perfil de trabalho.

\section{REFERÊNCIAS}

Arruda, A. (2002). As representações sociais: Desafios de pesquisa. Revista de Ciências Humanas, (6), 09-23. doi:10.5007/\%25x

Arruda, A. (2005). Despertando do pesadelo: A interpretação. In Moreira, A. S. P.; Camargo, B.V.; Jesuíno, J.C.; \& Nóbrega, S. M. (Orgs.), Perspectivas teórico-metodológicas em representações sociais (2a. ed., pp. 229-258). João Pessoa, PB: UFPB. 
Cellard, A. (2008). A análise documental. In J. Poupart, J.-P Deslauriers, L.-H. Groulx, A. Laperrière, R. Mayer, \& A. P. Pires, A pesquisa qualitativa: Enfoques epistemológicos e metodológicos (pp. 295-316). Petrópolis, RJ: Vozes.

Creswell, J. W. (2010). Projetos de pesquisa: Métodos qualitativos, quantitativos e mistos (3a. ed.). Porto Alegre, RS: Artmed.

Crubelatte, J. M. (2004). Participação como controle social: Uma crítica das estruturas organizacionais flexíveis. RAE-eletrônica, 3(2). Recuperado de www.rae.com.br/eletronica/index.cfm?FuseAction=Artigo\&ID=1 611\&Secao=FOR.ESTCRI\&V.

Demo, P. (1992). Cidadania Menor - algumas indicações quantitativas de nossa pobreza política. Petrópolis, RJ: Vozes.

Denhardt, J. V., \& Denhardt, R. B. (2003). The new public service: Serving rather than steering. New York, NY: M.E. Sharpe.

Denhardt, R. B. (2012). Teorias da Administração Pública. São Paulo, SP: Cengage Learning.

Doin, G. A., Dahmer, J., Schommer, P. C., \& Spaniol, E. L. (2012). Mobilização social e coprodução do controle: O que sinalizam os processos de construção da lei da ficha limpa e da Rede OSB de controle social. Pensamento \& Realidade, 27(2), 56-79.

Escola Nacional de Administração Pública. (2015). Curso de Controle Social e Cidadania. De Bona, Rodrigo da Silva; Kischlat, Everton, \& Cortes, Rebecca (Conteudistas).
Brasília: ENAP. Recuperado de http://repositorio.enap.gov.br/handle/1/2719.

Etkin, J. R., \& Schvarstein, L. (2005). Identidad de las organizaciones: invariancia $y$ cambio (6a. reimpressão). Buenos Aires: Paidos. (Obra original publicada em 1989)

Favretto, J., \& Riccio, E. L. (2017). Observatório Social do Brasil em números (E-Book). UNOESC, FEA/USP e TECSI (Eds.). Recuperado de http://osbrasil.org.br/wp-content/ uploads/2017/04/e-book-OSB-06-04-2017-2. pdf.

Godoi, C. K., \& Mattos, P. L. C. L. (2006). Entrevista qualitativa: Instrumento de pesquisa e evento dialógico. In C. K. Godoi, R. Bandeira-de-Mello, \& A. B. da Silva, (Orgs.), Pesquisa Qualitativa em estudos organizacionais - paradigmas, estratégias e métodos (pp. 301-323). São Paulo, SP: Saraiva.

Godoy, A. S. (2006). Estudo de caso qualitativo. In C. K. Godoi, R. Bandeira-de-Mello, \& A. B. da Silva (Orgs.), Pesquisa Qualitativa em estudos organizacionais - paradigmas, estratégias e métodos (pp. 115-146). São Paulo: Saraiva.

Guerzovich, F., \& Schommer, P. C. (2016). Four ways in which social accountability and open government interventions bridge the state and society. 12th ISTR Conference - Ersta Sköndal University College. Suécia: ISTR Conference Working Paper Series, Vol. $\mathrm{X}$.

Heidemann, F. G. (2009). Ética de responsabilidade: Sensibilidade e correspondência a promessas e expectativas contratadas. In F. G. Heidemann, \& J. F. Salm (Orgs.), Políticas 


\section{OBSERVATÓRIO SOCIAL DO BRASIL E OS DESAFIOS ORGANIZACIONAIS DO CONTROLE SOCIAL}

públicas e desenvolvimento: Bases epistemológicas e modelos de análise (pp. 301309). Brasília, DF: UnB.

Jodelet, D. (2001). Representações Sociais: Um domínio em expansão. In D. Jodelet (Org.). As representações sociais (pp. 187203). Rio de Janeiro, RJ: UERJ.

Jodelet, D. (2009). O movimento de retorno ao sujeito e a abordagem das representações sociais. Sociedade $e$ Estado, 24(3), 679-712. doi:10.1590/S010269922009000300004

Jodelet, D. (2011). Sobre o movimento das representações sociais na comunidade acadêmica brasileira. Temas em Psicologia, 19(1), 19-26.

Jovchelovitch, S. (2008). Vivendo a vida com os outros: Intersubjetividade, espaço público e Representações Sociais. In P. A. Guareschi , \& S. Jovchelovitch. (Orgs). Textos em Representações Sociais (10a. ed., pp. 63-85). Petrópolis, RJ: Vozes.

Jovchelovitch, S., \& Priego-Hernandez, J. (2013). Sociabilidades subterrâneas: Identidade, cultura e resistência em favelas do Rio de Janeiro. Brasília, DF: Unesco.

Lopes, M. J. M., \& Bueno, A. L. M. (2007). Saúde Pública é...: Permanências e modernidades nas representações de universitários. Saúde e Sociedade, 16(3), 92-101. doi:10.1590/S0104-12902007000300009

Morin, E. (1991). O método IV. As ideias: Sua natureza, vida, habitat e organização. Portugal: Publicações Europa-América.
Morin, E. (1998). Ciência com consciência (2 ${ }^{\mathrm{a}}$ ed.) Rio de Janeiro, RJ: Bertrand Brasil.

Morin, E. (2015). Introdução ao pensamento complexo ( $5^{\mathrm{a}}$ ed.). Porto Alegre, RS: Sulina.

Morin, E., \& Kern, A. B. (1995). Terra-pátria. Porto Alegre, RS: Sulina.

Moscovici, S. (2015). Representações sociais: Investigações em psicologia social (11a. ed.). Petrópolis, RJ: Vozes.

Nogueira, F. A., \& Alves, M. A. (2014). Associações civis podem ser escolas democráticas? Efeitos de algumas características organizacionais. Administração Pública e Gestão Social, 6(1), 2-10. doi:10.21118/ apgs.v6i1.584

O'Donnell, G. (1998). Accountability horizontal e novas poliarquias. Lua Nova, (44), 2757. doi:10.1590/S0102-64451998000200003

Observatório Social do Brasil. (2017a). Institucional. Recuperado de http://osbrasil.org. br/observatorios-pelo-brasil.

Observatório Social do Brasil. (2017b). Ato Administrativo no. 001-2017. Recuperado de http://osbrasil.org.br/wp-content/ uploads/2017/01/OSB_ato-admvo-001.17_ altera\%C3\%A7\%C3\%A3o-de-repres.-un. admva_.SC_.pdf.

Ostrom E. (1996). Crossing the great divide: Coproduction, synergy and development. World Development, 24(6), 1073-1087. doi:10.1016/0305-750X(96)00023-X

Rocha, A. C. (2011). Accountability na Administração Pública: Modelos teóricos e abor- 
dagens. Contabilidade, Gestão e Governança, 14(2), 82-97.

Rocha, A. C., Spaniol, E. L., Schommer, P. C., \& Sousa, A. D. de. (2012). A coprodução do controle como bem público essencial à accountability. XXXVI EnANPAD. São Paulo: ANPAD, 22-26.

Schommer, P. C. (2014). State-Society Relationships in Brazil: Institutional architecture, accountability and coproduction of the public good. In P. M. E Mendonça, M. A. Alves., \& F. A. Nogueira. (Orgs.), The Institutional Architecture of Support to Civil Society Organizations in Brazil (pp. 181-205). São Paulo, SP: FGV.

Schommer, P. C., Rocha, A. C., Spaniol, E. L., Dahmer, J., \& Sousa, A. D. (2015). Ac- countability and co-production of information and control: Social observatories and their relationship with government agencies. Revista de Administração Pública, 49(6), 1375-1400.

Sierra, F. (1998). Función y sentido de la entrevista cualitativa en investigación social. In L. J. G. Cáceres. (Coord.). Técnicas de investigación en sociedad, cultura y comunicación (pp. 277-346). México: Prentice Hall.

Vergara, S. C. (2010). Métodos de pesquisa em Administração (4a. ed.). São Paulo, SP: Atlas.

Wood, T., Jr., \& Caldas, M. P. (1997). Identidade Organizacional. RAE-Revista de Administração de Empresas, 37(1), 6-17. 